Journal of Systems Science and Information

Oct., 2014, Vol. 2, No. 5, pp. 428-436

DOI: $10.1515 /$ JSSI-2014-0428

\title{
Design and Pricing of Chinese Contingent Convertible Bonds
}

\author{
Ping LI \\ Department of Finance, Beihang University, Beijing 100083, China \\ E-mail:Lipingxx@126.com \\ Jie LIU \\ Department of Finance, Beihang University, Beijing 100083, China \\ E-mail: xingtailiujie564@sina.com
}

\begin{abstract}
The financial crisis since 2007 has highlighted the fragility of the banking system. To address this deficiency, the Basel committee has agreed upon Basel III which consists of reinforcing banks' capital through new regulatory requirements. Raising additional funds by issuing common equity would lead to a significant cost for banks. Facing the problem, regulators came up with the concept of contingent capital. Contingent convertible ( $\mathrm{Coco}$ ) bonds have been the topic as both a solution to the "too big to fail" problem and a measure by which financial institutions can save themselves. In this paper we first give the introduction of Coco bonds, then present the design of Chinese Coco bonds and pricing Coco bonds through an equity derivative approach as well as sensitivity analysis based on B-S-M hypothesis. Considering that the stock return follows fat-tail distribution, this paper uses Heston stochastic volatility model to price Coco bonds. Finally we give some proposals for developing Coco bonds market in China.
\end{abstract}

Keywords contingent convertible (Coco) bonds; barrier option; stochastic volatility model

\section{Introduction}

The financial crisis since 2007 has highlighted the fragility of the banking system. To address this deficiency, the Basel committee has agreed upon Basel III which consists of reinforcing bank's capital through new regulatory requirements. Raising additional funds by issuing common equity would lead to a significant cost for banks. To solve this problem, regulators are considering whether capital may be raised in other forms which are less expensive, for example through contingent capital such as contingent convertible (Coco) bonds. Coco bond is hybrid capital bonds with dual characteristics of equity capital and debt instrument. Therefore, from the perspective of supplying capital adequacy, Coco bonds are also known as contingent capital bonds.

There are three main strands on Coco bonds. The first one aims to achieve an optimal capital structure by choosing different parameters of debts ${ }^{[1]}$. The second one suggests a dual-trigger: one is set by regulators and the other one set by the bank ${ }^{[2,3]}$. With the increased interests from regulators on banking prudential policy, countercyclical contingent capital (CCC) whose

Received January 2, 2014, accepted March 24, 2014

Supported by the National Natural Science Foundation of China (No. 71271015, 70971006) 
conversion is decided by a regulatory authority is becoming an important branch ${ }^{[4,5]}$. The third strand focuses on valuation aspects of Coco bonds using different mathematical models ${ }^{[6]}$.

Since the concept of Coco bonds is put forward not for a long time, the pricing model for Coco bonds is rare. We can use the development history of convertible bonds pricing for reference and derive the way of Coco bonds pricing. The publishing of the paper by Black and Scholes ${ }^{[7]}$ marked the traditional imprecise option pricing theory was replaced by the new precise option pricing theory. Later, on the basis of new option pricing model, the convertible bonds pricing model was quickly developed. Ingersoll first used the Black-Scholes-Merton model to price convertible bonds ${ }^{[8]}$. The techniques underlying the Black-Scholes-Merton Option model were used to price convertible securities as contingent claims on the firm as a whole. Brennan and Schwartz got the price of convertible bonds by means of finite difference method ${ }^{[9]}$. Jan De Spiegeleer provided an in-depth analysis of pricing and structuring of contingent convertibles and applied two approaches to tackle the pricing and structuring of Coco bonds: the credit derivatives approach and the equity derivatives approach ${ }^{[6]}$.

In this paper, we will design the Coco bonds suitable for China and price Coco bonds through an equity derivatives approach. The remaining of the paper is arranged as follows: We first give the design of Chinese Coco bonds, such as the specification of trigger events and conversion price in Section 2; then in Section 3 we give the pricing formulas for Coco bonds using the equity derivatives and stochastic volatility approaches, respectively. In Section 4 we use a numerical example to demonstrate how to price a Chinese Coco bond using the two approaches and then make the sensitivity analysis with respect to four impacting factors. Section 5 concludes the paper.

\section{Design of Chinese Coco bonds}

So far there have been many discussions about the basic ideas of Coco bonds. Scholars have put forward different design proposals and specific intentions, but the same goal is to use Coco bonds to rebuild the bank capital structure.

\section{$2.1 \quad$ Trigger event}

The trigger event means the circumstances in which a bond will be converted into equities or a write-down will occur. When structuring Coco bonds, the trigger conditions should satisfy some important characteristics such as clarity, objectivity, transparency and publicity. In general, four kinds of trigger event can be used: the accounting trigger, the market trigger, the multi-variate trigger and the regulation trigger. Considering the complexity and differentiation of banking institutions in China, and the prevention of systemic risk, we claim that double triggers should be used.

\subsection{Conversion price}

A Coco bond investor is better off when the conversion price is low, which results in more shares when conversion takes place, while the outstanding shareholders are worse off when the conversion price is low. At the same time, low conversion price will lead to a higher dilution of their initial equity investment, so the level of conversion price has an important impact on the dynamic behavior of the Coco bond and its fair value. In practice three choices of conversion 
price are possible: price on trigger time, price on issue time and conversion price with a floor.

Comparing with the choice of trigger price and restrictions to a specific price, this paper claims that conversion price on trigger time is more favorable for banks. When using price on trigger time as conversion price, the lower price will dilute existing shareholders' holdings. In order to prevent the happening of trigger, bank shareholders have great incentive to raise new capital to increase capital adequacy ratio. Using price on trigger time as conversion price can also reduce the issue cost of Coco bonds. When giving Coco bond holder's lower conversion price, the required return will be decreased.

\section{Coco bonds pricing models}

\subsection{Equity derivative approach}

In equity derivatives approach, we price Coco bonds by finding a portfolio of equity derivative that replicate the cash flow of Coco bonds. If the replicating portfolio produces the same cash flows as the Coco bonds, then the cost of the replicating portfolio must be the price of Coco bonds. The payoff $\mathrm{Coco}_{T}$ of a Coco bond in case of conversion resembles that of a knock-in forward (KIF) with barrier price $S_{\text {trig }}$.

$$
\operatorname{Coco}_{T}= \begin{cases}N S_{T}, & \text { if } \min \left(S_{t}\right)_{t \leq T} \leq S_{\text {trig }} \\ F, & \text { otherwise }\end{cases}
$$

where, $N$ is the number of shares that Coco bonds holders get if converted, $S$ is the stock price, $F$ is the face value of Coco bond, and $T$ is the maturity of the Coco bond.

The cash flow can be rewritten as:

$$
\begin{aligned}
\operatorname{Coco}_{T} & =F+\left(F S_{T} / C_{p}-F\right) 1_{\left\{\min \left(S_{t}\right)_{t \leq T} \leq S_{t r i g}\right\}}=F+N\left(S_{T}-F / N\right) 1_{\left\{\min \left(S_{t}\right)_{t \leq T} \leq S_{t r i g}\right\}} \\
& =F+N\left(S_{T}-C_{p}\right) 1_{\left\{\min \left(S_{t}\right)_{t \leq T} \leq S_{t r i g}\right\}}
\end{aligned}
$$

where, $C_{p}$ is the conversion price.

So we have,

$$
\text { Coco } \approx C B+K I F
$$

where, $C B$ is the value of a regular bond, and $K I F$ is the value of a knock-in forward.

A long position in KIF is equivalent to a long position in knock-in call (KIC) and a short position in knock-in put (KIP), that is:

$$
K I F_{T}=K I C_{T}-K I P_{T}
$$

where

$$
\begin{aligned}
& K I C_{T}= \begin{cases}S_{T}-C_{p}, & \text { if } S_{T}>C_{p}, \min \left(S_{t}\right)_{t \leq T} \leq S_{\text {trig }}, \\
0, & \text { otherwise. }\end{cases} \\
& K I P_{T}= \begin{cases}C_{p}-S_{T}, & \text { if } S_{T}<C_{p}, \min \left(S_{t}\right)_{t \leq T} \leq S_{\text {trig }}, \\
0, & \text { otherwise. }\end{cases}
\end{aligned}
$$

We first compute KIC. Define

$$
x= \begin{cases}1, & \text { if } S_{T}>C_{p}, \quad \min \left(S_{t}\right)_{t \leq T} \leq S_{\text {trig }} \\ 0, & \text { otherwise }\end{cases}
$$


From Back and Heston we know that the value of $K I C$ at maturity is $K I C_{T}=x\left(S_{\text {trig }}-C_{p}\right)$, and the value at time $t$ is $^{[10,11]}$ :

$$
K I C_{t}=\mathrm{e}^{-q(T-t)} S_{0} \operatorname{Pr}^{V}(x=1)-\mathrm{e}^{-r(T-t)} C_{p} \operatorname{Pr}^{R}(x=1)
$$

where, $q$ is the dividend yield, $r$ is the continuously compounded risk-free rate, $V$ is the dividend accumulation factor, and $R$ is the risk-free accumulation factor, that is $V(t)=\mathrm{e}^{q t} S(t), R(t)=$ $\mathrm{e}^{r t}$.

Let $L$ denote the lower barrier for the down-and-in call and assume that it has not yet been breached at the valuation date. Then we have

$$
\operatorname{Pr}^{V}\left(S_{T} \leq L\right)=N\left(d_{1}^{i}\right), \quad \operatorname{Pr}^{R}\left(S_{T} \leq L\right)=N\left(d_{2}^{i}\right)
$$

where, $d_{1}^{i}=\frac{\ln \left(S_{t} / S_{t r i g}\right)+\left(r-q+\sigma^{2} / 2\right) T_{i}}{\sigma \sqrt{\left(T_{i}-t\right)}}, d_{2}^{i}=d_{1}^{i}-\sigma \sqrt{\left(T_{i}-t\right)}$.

$$
\begin{gathered}
\operatorname{Pr}^{V}(x=1)=\left(\frac{S_{\text {trig }}}{S_{t}}\right)^{2\left(r-q+\frac{1}{2} \sigma^{2}\right) / \sigma^{2}} N\left(\tilde{d}_{1}^{i}\right) . \\
\operatorname{Pr}^{R}(x=1)=\left(\frac{S_{\text {trig }}}{S_{t}}\right)^{2\left(r-q-\frac{1}{2} \sigma^{2}\right) / \sigma^{2}} N\left(\tilde{d}_{2}^{i}\right) . \\
\tilde{d}_{1}^{i}=\frac{\ln \left(S_{\text {trig }} / S_{t}\right)+\left(r-q+\sigma^{2} / 2\right) T_{i}}{\sigma \sqrt{T_{i}-t}}, \quad \tilde{d}_{2}^{i}=\tilde{d}_{1}^{i}-\sigma \sqrt{T_{i}-t} .
\end{gathered}
$$

Therefore, the value of down-and-in call (KIC) at time $t$ is:

$$
K I C_{t}=S_{t} \mathrm{e}^{-q\left(T_{i}-t\right)}\left(\frac{S_{\text {trig }}}{S_{t}}\right)^{2\left(r-q+\frac{1}{2} \sigma^{2}\right) / \sigma^{2}} N\left(\tilde{d}_{1}^{i}\right)-\mathrm{e}^{-r(T-t)} C_{p}\left(\frac{S_{\text {trig }}}{S_{t}}\right)^{2\left(r-q-\frac{1}{2} \sigma^{2}\right) / \sigma^{2}} N\left(\tilde{d}_{2}^{i}\right)
$$

Similarly, the value of down-and-in put (KIP) at time $t$ is:

$$
K I P_{t}=C_{p} \mathrm{e}^{-r\left(T_{i}-t\right)} N\left(-d_{2}^{i}\right)-S_{t} \mathrm{e}^{-q(T-t)} N\left(-d_{1}^{i}\right)
$$

As a result, the value of the Coco bond at time $t$ is:

$$
C o O_{t}=\mathrm{e}^{-r(T-t)} F+N \times\left(K I C_{t}-K I P_{t}\right)
$$

The above is the formula for a zero coupon Coco bond. When considering the coupon, each coupon payment can be replicated by a short position in a binary down-and-in call with the maturity corresponding to each of the coupon dates. Consequently, the price at time $t$ of a Coco bond with coupons $\tilde{C}$ ocot will be reduced by the sum of the values of all binary down-and-in calls (BDIC).

$$
\tilde{C} \text { oco }_{t}=\mathrm{Coco}_{t}-\sum_{i} B D I C_{i}
$$

The value of each binary down-and-in call is:

$$
B D I C_{i}=\text { Coupon }_{i} \times \mathrm{e}^{-r\left(T_{i}-t\right)} \times\left[N\left(-d_{1}^{i}+\sigma \sqrt{T_{i}-t}\right)+\left(S / S_{\text {trig }}\right)^{2\left(r-q-\frac{1}{2} \sigma^{2}\right)} N\left(\tilde{d}_{1}^{i}-\sigma \sqrt{T_{i}-t}\right)\right]
$$


In conclusion, the pricing formula for a Coco bond is:

$$
\begin{aligned}
& \tilde{C} \text { oco }_{t} \\
& =\mathrm{e}^{-r(T-t)} F+N \times\left(K I C_{t}-K I P_{t}\right) \\
& -\sum\left\{\text { Coupon }_{i} \times \mathrm{e}^{-r\left(T_{i}-t\right)} \times\left[N\left(-d_{1}^{i}+\sigma \sqrt{T_{i}-t}\right)+\left(S / S_{\text {trig }}\right)^{2\left(r-q-\frac{1}{2} \sigma^{2}\right)} N\left(\tilde{d}_{1}^{i}-\sigma \sqrt{T_{i}-t}\right)\right]\right\}
\end{aligned}
$$

\subsection{The Heston stochastic volatility approach}

Black-Scholes-Merton's model is widely employed as a useful approximation of Coco bonds' price, because it is easy to calculate from the explicit closed-form formula. However, empirical evidences suggest that the key assumption of constant volatility of the Black-Scholes-Merton model is not reasonable. The distribution of stock prices tends to have fatter tails than the distribution of prices that geometric Brownian motion implies. That is, the Black-Scholes-Merton model underestimates the risk of extreme events. In recent years the stochastic volatility model is thought to be a better model than the Black-Scholes-Merton model, since stochastic volatility models are based on the assumptions that the volatility of stock price follows a stochastic process. The most popular stochastic volatility model is the following Heston model ${ }^{[11]}$ :

$$
\begin{aligned}
& \mathrm{d} S_{t}=S_{t}(r-q) \mathrm{d} t+S_{t} \sqrt{\nu_{t}} \mathrm{~d} B_{t}, \\
& \mathrm{~d} \nu_{t}=\kappa\left(\bar{\nu}-\nu_{t}\right) \mathrm{d} t+\sqrt{\nu_{t}} \sigma_{v} \mathrm{~d} B_{\nu} .
\end{aligned}
$$

where, $\kappa$ is the mean reversion coefficient, $\bar{\nu}$ is the long run mean reversion level, $\sigma_{v}$ is the volatility of volatility $\nu, \rho$ is the correlation between the stock price and volatility.

From the Heston model the value of a Coco bond with coupon can be computed as follows:

$$
\tilde{C} \text { oco }_{t}=E^{Q}\left[\left(\mathrm{e}^{-r(T-t)} F+C_{T}\right) 1_{\{\tau>T\}}+\mathrm{e}^{-r(T-t)}\left(N S_{\text {trig }}+C_{\tau}\right) 1_{\{\tau \leq T\}}\right]
$$

where, $\tau$ is the trigger time, $T$ is the maturity of Coco bond, and $C$ is the value of the coupon, $C_{\tau}$ and $C_{T}$ are the accumulated coupons to the trigger time and maturity, respectively.

\section{Numerical pricing for Chinese Coco bonds}

\subsection{Numerical pricing using the equity derivative approach}

Assume that Minsheng Bank issued a Coco bond on February 1, 2012. Its items are shown in the following Table 1.

Table 1 Details of Minsheng Coco bond

\begin{tabular}{ll}
\hline Company name & China Minsheng Banking co, LTD \\
\hline Issue date & February 1, 2012 \\
Issuance (billion) & 4 \\
Price (RMB) & 100.00 \\
Denomination & 100.00 \\
Duration & 10 \\
Trigger event & 30 -day moving average stock price $<2$ and regulators $(\mathrm{CBRC})$ announce that \\
& the banking system is in systemic crisis \\
Conversion price & Price on trigger time \\
\hline
\end{tabular}


On February 1, 2013, Minsheng Bank stock price was 11.23, risk free rate was 0.028 using the return rate of one-year fixed-rate bonds, stock dividend rate was 0.05 , and the volatility was 0.23. Then from Equation (11) the price of the Coco bond is 73.74 Yuan.

According to the historical data of Minsheng Bank stock price, we can calculate the prices for the Minsheng Coco bond for the period from February 1, 2012 to February 1, 2013 and results are shown in Figure 1. For comparison, we also give the corresponding stock price series.

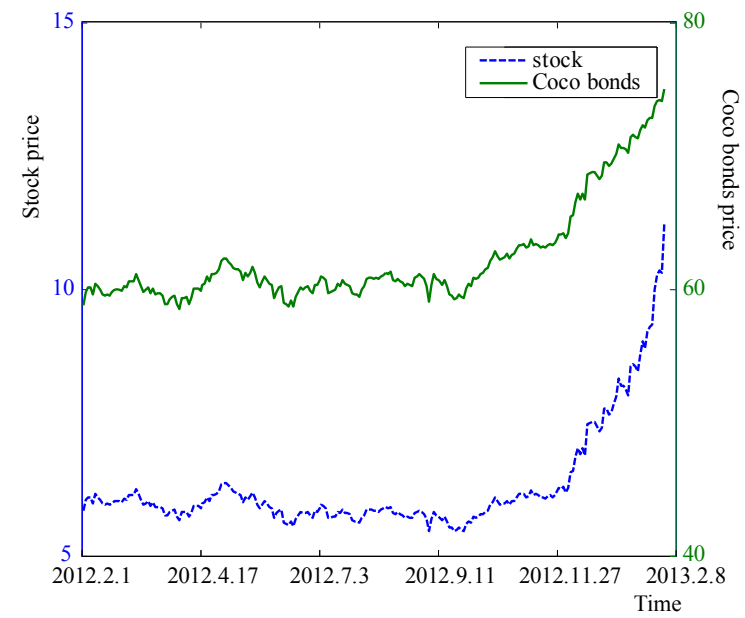

Figure 1 Prices of the stock and Coco bond of Minsheng Bank

\subsection{Sensitivity analysis}

In this subsection we make the sensitivity analysis for the Coco bond prices with respect to some impacting factors. From Section 2 we know that a zero coupon Coco Bond is composed of a regular bond and a knock-in forward. Since the price of the regular bond is not affected by conversion price $C_{p}$, trigger price $S_{\text {trig }}$, stock price $S$ and the volatility of stock price $\sigma$, the price of zero coupon Coco bond is only affected by the knock-in forwards. Figures 2 to 5 give the sensitivity analysis of the Coco bond prices as well as the credit spreads of the Coco bond with respect to conversion price $C_{p}$, trigger price $S_{\text {trig }}$, stock price $S$ and the volatility of stock price, respectively.
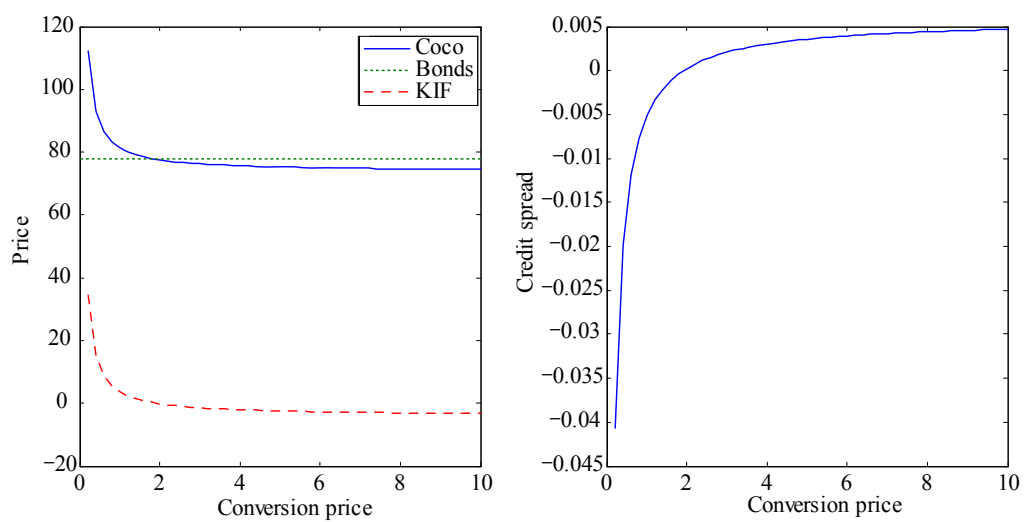

Figure 2 Sensitivity of Coco bond's prices and credit spreads with respect to the conversion price 
From Figure 2 we can see that as the conversion price goes up, if the Coco bonds are converted to stocks, Coco bond holders will get less number of stocks, and therefore, the price of Coco bond decreases and credit spread increases.
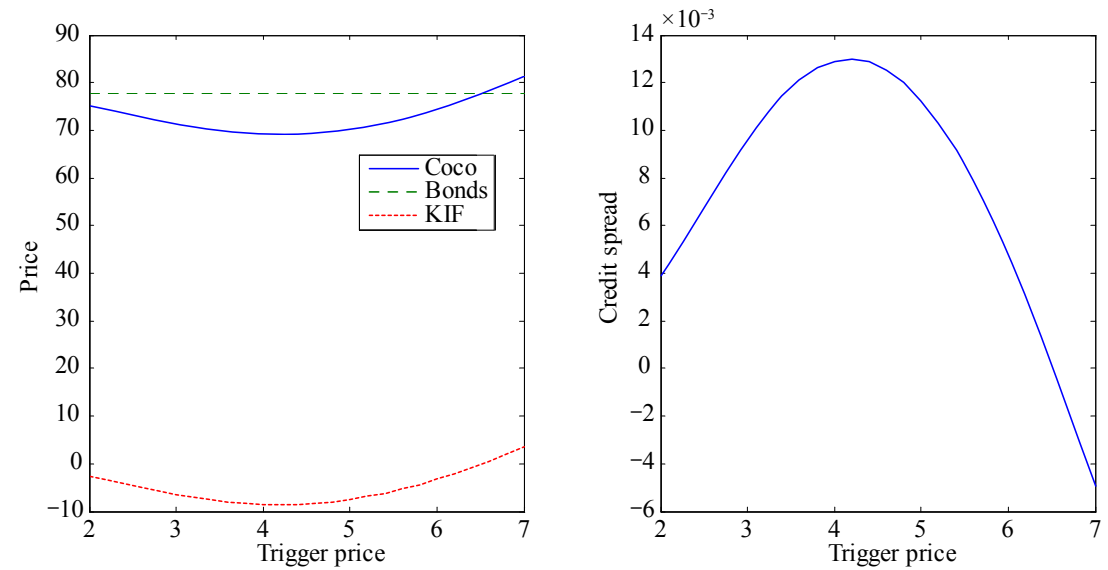

Figure 3 Sensitivity of Coco bond's prices and credit spreads with respect to the trigger price

From Figure 3 we can see that if the trigger price is high, then it is more likely to receive the forwards, but the forwards will have low price. Both of them two will make Coco bonds price and credit spread change as shown above.
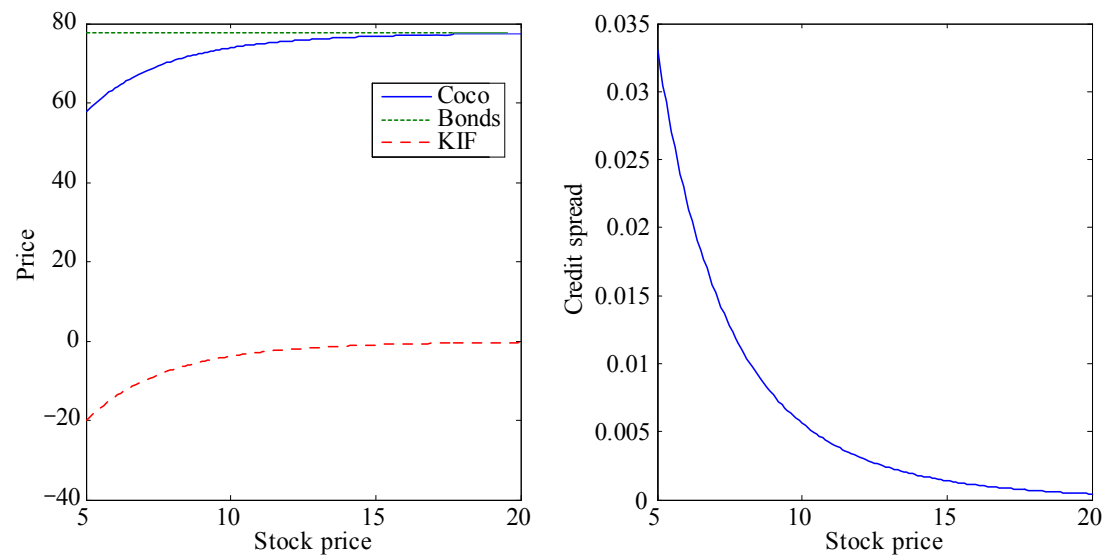

Figure 4 Sensitivity of Coco bond's prices and credit spreads with respect to the stock price

From Figure 4 we can see that as the stock price rises, the probability of knocking-in declines, so the prices of the KIF and Coco bond increase, and the credit spread decreases. This situation reflects that the bank is operating in a good condition.

While as the volatility increases, the probability of knock-in goes up, then the value of KIF becomes more negative, and the value of Coco bond declines, just as shown in Figure 5 .

The above sensitivity analysis shows that the pricing model of Coco bonds under the BlackScholes-Merton model is in accordance with economic sense. 

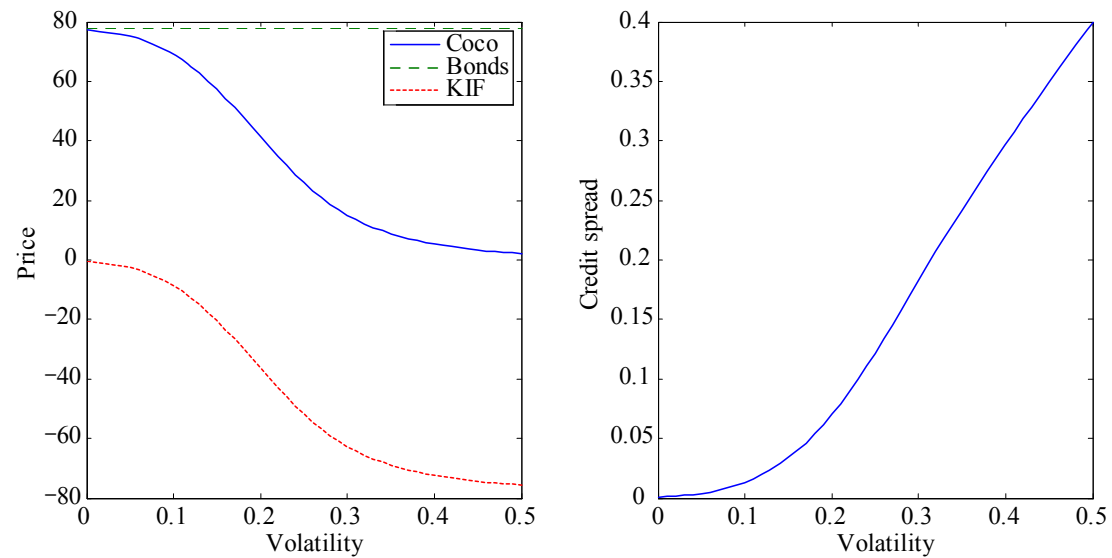

Figure 5 Sensitivity of Coco bond's prices and credit spreads with respect to the volatility

\subsection{Numerical pricing using the stochastic volatility approach}

Assume that the parameters in Heston model are $\sigma_{v}=0.44, \kappa=1.62, \rho=-0.76, \bar{\nu}=$ $0.0529^{[12]}$, then we can calculate the price for a Coco bond with coupon from Equation (12). Results are shown in Table 2, and for comparison, we also give the results calculated from the B-S-M model.

Table 2 Coco bond's price and credit spread based on B-S-M and Heston models

\begin{tabular}{lcc}
\hline & B-S-M & Heston model \\
\hline Price & 75.0528 & 72.4631 \\
Credit spread & 0.0039 & 0.0078 \\
\hline
\end{tabular}

It can be seen from Table 2 that compared with the B-S-M model, stochastic volatility model has lower price and higher credit spread.

\section{Conclusion}

In this paper we design a Coco bond suitable for China and then numerically price a Coco bond using the equity derivatives approach and Heston stochastic volatility model respectively.

Applying Coco bonds in Chinese financial market needs to consider the actual situation of China's financial market. When choosing trigger conditions, we consider the complexity and differentiation of banking institutions in China, and the prevention of systemic risk, so we claim that dual trigger is a better choice. Chinese financial market is still underdeveloped compared with developed financial markets, and information disclosure system remains to be imperfect, so trigger event does not only depend on the market value. Otherwise it will meet great risk of market manipulation.

Coco bond is still in its infancy, and faces many restrictive factors. But because of its effect on enterprises during the crisis, the development prospect is still worth looking forward to. To further promote the development of Coco bond market, the present international regulators 
need to establish better conversion framework, system environment and other aspects for Coco bonds.

\section{References}

[1] Barucci E, Del Viva L. Dynamic capital structure and the contingent capital option. Annals of Finance, 2013, 9(3): 337-364.

[2] French K, Baily M, Campbell J, et al. The Squam Lake Report: Fixing the financial system. Journal of Applied Corporate Finance, 2010, 22(3): 8-21.

[3] McDonald R L. Contingent capital with a dual price trigger. Journal of Financial Stability, 2013, 9(2): 230-241.

[4] De Martino G, Libertucci M, Marangoni M, et al. Countercyclical contingent capital (CCC): Possible use and ideal design. Banca d'Italia, 2010.

[5] Barucci E, Del Viva L. Countercyclical contingent capital. Journal of Banking \& Finance, 2012, 36(6): 1688-1709.

[6] De Spiegeleer J, Schoutens W. Pricing contingent convertibles: A derivatives approach. Journal of Derivatives, 2012, 20(2): 27.

[7] Black F, Scholes M. The pricing of options and corporate liabilities. The Journal of Political Economy, 1973: 637-654.

[8] Ingersoll Jr J E. A contingent-claims valuation of convertible securities. Journal of Financial Economics, 1977, 4(3): 289-321.

[9] Brennan M J, Schwartz E S. A continuous time approach to the pricing of bonds. Journal of Banking \& Finance, 1979, 3(2): 133-155.

[10] Back K. A course in derivative securities: Introduction to theory and computation. Springer, 2005.

[11] Heston S L. A closed-form solution for options with stochastic volatility with applications to bond and currency options. Review of Financial Studies, 1993, 6(2): 327-343.

[12] Bakshi G, Cao C, Chen Z. Empirical performance of alternative option pricing models. The Journal of Finance, 1997, 52(5): 2003-2049 